\title{
First Degree Family History Cancer Positive
}

National Cancer Institute

\section{Source}

National Cancer Institute. First Degree Family History Cancer Positive. NCI Thesaurus.

Code C160165.

The parents, siblings or children of an individual have a history of cancer. 